This is an electronic reprint of the original article. This reprint may differ from the original in pagination and typographic detail.

Author(s): Nurkka, Niina; Viiri, Jouni; Littleton, Karen S.; Lehesvuori, Sami

Title: $\quad$ A methodological approach to exploring the rhythm of classroom discourse in a cumulative frame in science teaching

Year: $\quad 2014$

Version:

Please cite the original version:

Nurkka, N., Viiri, J., Littleton, K. S., \& Lehesvuori, S. (2014). A methodological approach to exploring the rhythm of classroom discourse in a cumulative frame in science teaching. Learning, Culture and Social Interaction, 3(1), 54-63.

https://doi.org/10.1016/j.Icsi.2014.01.002

All material supplied via JYX is protected by copyright and other intellectual property rights, and duplication or sale of all or part of any of the repository collections is not permitted, except that material may be duplicated by you for your research use or educational purposes in electronic or print form. You must obtain permission for any other use. Electronic or print copies may not be offered, whether for sale or otherwise to anyone who is not an authorised user. 


\title{
A methodological approach to exploring the rhythm of classroom discourse in a cumulative frame in science teaching
}

\begin{abstract}
The purpose of this study is to characterise the nature and purpose of different types of classroom discourse and to explore how the rhythm of classroom discourse provides a cumulative frame for the teaching of science. The overall data consisted of a teaching sequence of eight lessons on the moment of force as taught to physiotherapy students at a Finnish University of Applied Sciences. Our in-depth multiple timescale analysis of two episodes illustrated in this study shows examples how cumulation was instantiated by the different types of classroom discourse. The methodology and findings of this study have implications both for teacher education and further research.
\end{abstract}

Keywords: classroom discourse, types of classroom discourse, cumulative teaching, cumulative rhythm

\section{Introduction}

The sociocultural perspective (e.g. Leach \& Scott, 2003; Mercer \& Littleton, 2007; Vygotsky, 1978) emphasises the importance of social interaction and language for constructing knowledge and understanding. Accordingly, science education is constituted as a discursive process, whereby novices are inducted into specific ways of representing and understanding phenomena by those more expert in the field (Mercer, 2004; Mercer, Dawes, Wegerif \& Sams, 2004). Acting as a mediator of 'the scientific view', the teacher has to ensure that the classroom discussion is conducted at an appropriate level and in a way suited to the learning aims (Mortimer \& Scott, 2003; Scott et al., 2006).

Classroom discussion, which supports students' learning and is suited to the aims of learning, has certain properties that cohere through the concept of 'dialogic teaching' (Alexander, 2004). Central to Alexander's dialogic teaching is the cumulative nature of teaching, whereby teachers and students build on their own and each other's ideas and chain them into coherent lines of thinking and enquiry. Research considering the cumulative nature and quality of teaching from the perspective of classroom discourse is needed because cumulation is arguably (Alexander, 2004) the most difficult (and perhaps the most important) criterion of dialogic teaching to achieve.

Many studies provide important insights that enable us to understand the role of discourse in science teaching, the meaning of cumulation in dialogic teaching and different characterisations of classroom discourse (e.g. Aguiar, Mortimer \& Scott, 2010; Alexander, 2004; Furtak \& Shavelson, 2009; Mortimer \& Scott, 2003; Mortimer \& Machado, 2000; Scott, Mortimer \& Aguiar, 2006; Viiri \& Saari, 2006). They do not, however, investigate the relation of rhythm and cumulation of discourse in different timescales. This study also extends existing research by examining classroom discourseparticularly with respect to the cumulation of teaching-from the perspective of temporality by addressing how talk develops in time through visual illustrations. This 
issue is limitedly addressed in previous studies on classroom discourse, which mostly provide information in tables and charts (Nassaji \& Wells, 2000; Polman, 2004). In this study, the temporal consideration is utilised by using multiple timescales in analysis and visual presentation of classroom discourse.

There is a pressing need for studies using different timescales as units of analysis, since, as Klette (2009) has shown, using different time scales may offer different interpretations and conclusions regarding the same lesson. In relation to this study, different time scales may also increase the insights into different presentations of classroom interactions.

Our purpose in this study is to give examples of a new method to analyse classroom discourse. With this method, it is possible to characterise the types and the purposes of the classroom discourse, and to explore how the rhythm of classroom discourse affords a cumulative frame for the teaching of science. Before introducing the methods of the study, an overview is provided to the theoretical background.

\section{Theoretical background}

In dialogic teaching purposefulness means that teacher plans and steers classroom talk with specific educational goals in mind. Cumulation must be used to steer the talk toward specific purposes. (Alexander, 2004.) Even if students are immersed in classroom discourse, coherent knowledge and purposeful understanding will not emerge naturally: they have to be actively pursued as pedagogic goals, through the use of carefully chosen, appropriate teaching strategies with which possibilities of continuities in the students' experience can be exploited (Mercer \& Littleton, 2007).

The cumulative quality of teaching, as discussed here, emphasises not only continuity (the teacher explicitly points out connections between new knowledge and concepts or topics learned earlier), but also deepening, expanding or highlighting the concept or topic to be learned. In our study, cumulation is also examined from the perspective of various types of classroom discourse. By cumulation of types of classroom discourse, we mean that when the same concept is reviewed, another type of classroom discourse may be used.

Cumulation of teaching can be related to continuity of teaching. In some studies (e.g. Ryder, Hind \& Leach, 2003; Tiberghien, Buty \& Le Maréchal, 2004), continuity is taken to mean that the teacher explicitly makes connections between new knowledge and concepts or topics learned earlier in the same lesson or in previous lessons. In cumulative teaching, a teacher consciously and actively makes connections between the contents of lessons and builds coherent lines in students' thinking and enquiry (Alexander, 2004). By using talk, the teacher provides a cumulative, continuing and contextual frame to enable students' involvement and engagement with new ideas and knowledge (Mercer \& Littleton, 2007, p. 42). In this study, we aim to seek how cumulation is depicted in a variety of specific discourse types. Within the cumulative variation of discourse types, students' ideas must explicitly be taken account.

In several studies of classroom interaction (e.g. Cazden, 1986; Sinclair \& Coulthard, 1975; Wells, 1999), one very common finding is that such interaction typically follows a three-part exchange structure. In this triadic IRF pattern, 'I' 
corresponds to the initiative of the dialogue by the teacher, normally with a question, ' $R$ ' stands for the student's response and ' $F$ ' refers to the feedback given by the teacher to the student's response. In the IRF pattern, the teacher maintains control in interactions with students (Mercer, Littleton \& Wegerif, 2004). In the IRF pattern, the third move from the teacher can have different functions and could more generally be understood as a followup move rather merely as feedback (Cullen, 2002). In some contexts it has a dominant, evaluative function, but it can also be: "an opportunity to extend the student's answer, to draw out its significance, or make connections with the student's experience" (Wells, 1999, p. 200). In line with this idea, Mortimer and Machado (2000) have aligned the IRF pattern with pedagogical aims by classifying the classroom discourse structure on the basis of the form of the third move action in the dialogue. The IRF pattern can be considered 'authoritative' as long as the feedback from the teacher is an evaluation-this can also be expressed by 'IRE', where ' $E$ ' stands for evaluation. In the case where the feedback (or the follow-up) supplies elements for a further extension of the response by the students, or elicits new ideas and contributions from them, the IRF pattern corresponds to a dialogic function.

In relation to more recent derivatives from classical interaction forms, student initiatives have also been recognised as having a role in shaping the forms of classroom discourses (Aguiar et al., 2010). Besides their potentiality to shape ongoing discussions, especially the teacher follow-up to student initiatives could give insights into the prevailing nature of discussions.

Based on actual classroom discourse analysis in Finnish physics lessons, Viiri and Saari (2006) extended the characterisation by Mortimer and Machado, dividing classroom discourse into five categories: teacher presentation (TP), teacher-guided authoritative discussion (AD), teacher-guided dialogic discussion (DD), peer discussion (PD) and other $(\mathrm{O})$. The different types of classroom discourse do not represent 'better' or 'worse' teaching strategies, as these different types of discourse can serve complementary functions.

The characterisation of Viiri and Saari resembles the concept of communicative approach developed by Mortimer and Scott (2003). Yet, whereas in Mortimer and Scott's categorisation system the identification of dialogic and authoritative approaches is based on evaluating sequential interaction patterns, Viiri and Saari describe different types of discourse in more micro-level. For example, in this categorisation system one talk pattern IRE could be considered as AD. In Mortimer and Scott's categorisation one pattern could be, for example, considered as authoritative passage within a dialogic episode, or vice versa, dialogic moment within authoritative episode. In this study we apply Viiri and Saari system, since the interest on any changes in discourse types forming a rhythm of discourse.

Because of the different purposes of the types of classroom discourse, any teaching sequence should include variation in discourse types (Mortimer \& Scott, 2003; Scott et al., 2006), and a teacher should also be able to change pre-planned classroom discourse types if and when necessary (Leach \& Scott, 2003). According to Mortimer and Machado (2000), this varying of the discussion type between authoritative and dialogic discussion forms the 'rhythm' of classroom discussion. Such a rhythm is dependent upon the teaching purposes and aims, with different types of discussion being used accordingly. 
Any variation in the type of discourse used during the discussion can be called a rhythm of discourse. An example of a rhythm could be the teacher opening up discussions with a specific type of classroom discourse and closing down with another type: opening up in a sense of taking account of diverging everyday ideas before closing down discussions with more scientific weight. This rhythm has been implicitly referred to Scott and Ametller (2007), yet in this paper this idea is taken further in terms of visualizing the shifts between different types of discourse constituting a cumulative frame. In this study the temporal aspect is taken more explicitly into account by adapting the idea of Scott and Ametller (2007).

In the cumulative rhythm of discourse it is necessary that the discourse includes dialogic discussion where the teacher opens up space for students to explore their views and experiences. In this study the types of discourse are analysed in the micro-level which enables defining the types of discourse more specific inside the episode. Even if the dialogic discussion is often used in opening the discussion, the cumulative episode can also begin with short authoritative discussion (AD) or teacher presentation (TP) where the teacher introduces the subject to students before the dialogic discussion. In the cumulative communication structure by Scott and Ametller (2007) the unit of analysis is different and the dialogic approach can be defined as dominant approach in the episode.

Work by Furtak and Shavelson (2009) provides some empirical support for the view that the variation of the types of discourse used in lessons builds students' conceptual change: teachers of students with higher learning gains were more likely to vary the kind of guidance (authoritative or dialogic) they provided compared to teachers of students with lower learning gains.

As introduced, this paper presents a study intended to characterise the nature and purpose of different types of classroom discourse used in the teaching of science. We are particularly interested in examining the variation of discourse types (rhythm of classroom discourse) and how such variation provides a cumulative frame for teaching. In the study, the subject that was taught was physics, but the results-and especially the methods-we present may also be applied in the teaching of other subjects.

\section{Methods}

\subsection{Designing and developing the teaching sequence}

This paper describes a part of a wider study (Nurkka, 2006), in which a teaching sequence of eight lessons on the moment of force was developed and evaluated. The sequence of teaching was designed for use in the context of physiotherapy training at the Finnish University of Applied Sciences. In the teaching experiment focused on in this paper, there were 23 students whose ages ranged from 21 to 43 years (average age was 26 years).

The teaching sequence was divided into four sessions of two lessons (each lesson lasted 45 minutes). Besides the traditional theoretical teaching, the moment of force was studied in groups with four to five students solving practical problems having to do with lever systems in the body, and doing some experiments with a lever and a static wheel. The lesson materials for the teacher included lesson plans that, in addition to teaching contents and timetable, featured indicative guidance with respect to various types of 
classroom discourse (presented as symbols for each set of teaching contents). Regardless of the planned lesson materials, the teacher was allowed to change the lesson plans whenever he/she found it reasonable or necessary.

\subsection{Data collection}

During the teaching sequence, various kinds of data were gathered. For the classroom discourse analysis, the primary sources of data were the video-recorded and transcribed lessons. The video data was analysed by using Atlas.ti software. Other data (pre- and post-tests, interviews of the teacher and students, timetables and lesson plans) were used as additional resources to support the understanding of temporality with respect to an individual episode or a chain of episodes.

Two specific episodes were selected for in-depth analysis. In our study, an episode is identified as a period of teaching that deals with certain content and constitutes an entirety that is important from the perspective of learning aims. The specific reasons for selecting these two episodes for our classroom discourse analysis were that: i) cumulation took place on both the content level and the level of talk types; and ii) according to the teacher's and students' opinion, the episodes seemed to be important for students' learning (based on data from interviews and post-tests, Nurkka, 2006). Exemplifying our approach to the temporal analysis of classroom discourse, we present an in-depth analysis of two selected episodes derived from a teaching sequence of eight lessons.

\subsection{Analytical framework}

\subsubsection{Application of the theoretical background}

Given the rationale in the introduction and theoretical background, in this study we aim to:

a) Illustrate the variation of discourse types (rhythm of classroom discourse) and how such variation provides a cumulative frame for teaching. More specifically, examples of discourse types and cumulative rhythm are presented. And;

b) Address how talk develops in time through visual illustrations and detect distinct cumulative rhythms from these visual illustrations.

To access the research aims, the types of classroom discourse in the selected episodes were first categorised on the basis of the classification method developed by Viiri and Saari (2006). To make the students' role in classroom interactions more evident, we extended this classification method by developing a new category called 'student's initiative' (SI). Students' initiatives could give further confirmation about the teacher's intentions. For instance, if the teacher repeatedly follows student initiatives with evaluative feedback, he/she most likely aims to introduce scientific views rather than open up space for more dialogic discussions. In this sense, the teacher's responses could more clearly reveal the nature of discussions in the temporal frame of student initiatives. 
Characteristic of 'student's initiative' is that a student asks a question or takes an initiative that elicits new ideas or directs the teacher to clarify the ideas under discussion.

The feedback from the teacher on a student's initiative can be authoritative or dialogic. The introduction of this new category also resulted in some extensions being added to other categories: The category teacher-guided authoritative discussion was extended by adding the characteristic 'teacher's evaluative or unambiguous answer to student's initiative', and teacher-guided dialogic discussion was extended by adding the characteristic 'dialogic discussion after student's initiative'.

To make the classroom discourse analysis more reliable, two episodes were analysed by a second classifier who was familiar with the classification method used in this study. The compatibility between the analysis of the researcher and the second classifier was high (almost 100\%), and subsequently the second classifier was not needed in the analysis of other episodes.

In the analysis of the types of classroom discourse, the triadic IRE interactionor, more specifically, the chains of interactions IRFRFRF and IRFRFRE-were used in categorising the type of classroom discourse as either an authoritative discussion or a dialogic discussion. In the interaction, which began with an initiative from the teacher (I), the classroom discourse was classified as having been the same type of discourse throughout the whole interaction. The IRE (' $E$ ' for evaluative feedback from the teacher) pattern was classified as a teacher-guided authoritative discussion (AD) (for an example, see the first interaction in Table 2, in the Results section), and the chains of interactions IRFRFRF and IRFRFRE were classified as a teacher-guided dialogic discussion (DD) (for examples, see turns 1-14 and turns 15-22 in Table 1). In the classification of what comprises a teacher-guided discussion, we interpreted the kinds of interactions where teacher-guided dialogic discussion was followed by brief, evaluative feedback as showing that a teacher-guided dialogic discussion can also end with evaluative feedback from the teacher (see turn 14 in Table 1). In the analysis of the classroom discourse, the teacher's talk can be divided into two interactions (see Table 1, turns 14 and 15). The first part of the talk ends the previous interaction, and the end of the talk begins a new interaction. Where the classroom interactions begin with a student's initiative (SI), the interaction forms used were SIE and SIFRFRF. If an interaction began with a student's initiative (SI), then the initiative was classified as being one type of classroom discourse (SI), and the rest of the interaction as being another type (for example, see turns 24-27 in Table 1).

\subsubsection{Data analysis}

The analysis of the classroom discussion was conducted on three analytical levels: micro, meso and macro. As the temporal scales of these three levels have been understood and applied in different ways (Scott, Mortimer \& Ametller, 2011; Tiberghien \& Malkoun, 2009), the basis for the multi-level analysis in this study is presented in the following paragraphs.

In the analysis, the episodes were first divided into topics (see Figures 1 and 2 in the Results section). In the division of episodes to topics the main principle was that every topic dealt with certain sub-content and revealed a whole where a certain concept was discussed. When the classroom discourse moved forward dealing another concept, it 
was also defined to another topic. Every topic also had a certain purpose as introduce, explore or review the concept dealt in the topic. The types of discourse were analysed within the topic that addresses the micro-level of analysis that takes places on the level of turns and sentences. In the micro-level analysis the topics are the temporal boundaries for analysis. Within this level of analysis, interaction forms are defined in order to make explicit their relation to the discourse types. The micro-level analysis draws on the general principles of sociocultural discourse analysis (Mercer, 2004), an approach less focused on language itself and more on the functions language serves for joint activities.

Analysing the discourse types topic by topic made it possible to identify which type of discourse the teacher used for which purpose and how the rhythm of discourse unfolded in dealing with the particular sub-content of the topic. Although we have studied the episodes by dividing them into topics, it is only an 'analytic lens' or representational device for the purpose of our research. The actual teaching was not divided into these topics like unconnected fragments; the teacher proceeded fluently from one topic to the next.

Especially in relation to the second research aim, the visual illustrations (Figures 1 and 2) provide a view of this fluent development of talk and reveal distinct rhythms of discourse. Thus, in addition to revealing the different discourse types in the vertical axis, the horizontal axis illustrates the dynamic aspect of discourse and shifts between discourse types. We are especially interested in rhythms fostering the cumulative development of ideas, which could take place for instance by the teacher opening up discussions with a certain discourse type (usually dialogic) and closing it down with another (usually authoritative). The visual illustrations also address the meso-level of analysis by providing a more overall view of the talk. Briefly, on this level of analysis, rhythms of discourse are identified and illustrated in the lesson figures.

At the meso-level, the rhythms of talk are firstly examined within topics. However, since the teaching purposes of the topics are defined and presented in the figures, also preliminary notions about the rhythm between topics may be brought up and discussed. That is to say, some interpretations may be presented about the relation between the purposes of the talk and the prevailing discourse types. By prevailing discourse type, it is meant that a certain discourse type is distinctly dominant in a topic, while furthermore serving a specific teaching purpose.

The macro-level comes into question when analysing the overall communications taking place in an episode. Simply, teaching could be referred to as authoritative or dialogic. Or, as valued within this study, teaching could consist of several talk types resembling in this way a varying approach to the overall communications in an episode.

\section{Results}

In this section, we present two different transcribed examples from two different episodes. The selection of the examples originates from the purpose of this study, which is to illustrate the exemplary rhythms of cumulation. After giving a content-level confirmation of the cumulative rhythm of talk, similar rhythms are pointed out from lesson figures illustrating the talk types (Figures 1 and 2). In addition, other distinct rhythms are brought up and discussed. Before giving detailed information about the 
results, each episode will be introduced in terms of foregrounding the context in which the teaching took place.

\subsection{Episode 1}

In episode 1, the aim was to motivate the students to study the moment of force and related concepts by presenting them with the concepts in the context of a practical situation relevant to their future profession. The motivational process had already commenced in the previous episode, where several applications of moment of force in a physiotherapeutic context were briefly introduced to the students. A characteristic of episode 1 is that the students were very active during the episode. Students' activity was revealed through the ways in which the students participated in the teacher-guided classroom discussion and through several students' initiatives (Figure 1). Episode 1 lasted 13.5 minutes.

Episode 1 was divided into eight topics (Figure 1). Even if the topic was earlier defined to deal with the certain concept, the same concept could be considered in more than one topic during the same episode if some other concepts has been dealt in between and the sub-contents of the topics differ. For example topics 2, 5 and 8 all deal with the centre of gravity but they are defined to be different topics since in between, the concepts other than the centre of gravity are dealt with and the sub-contents of the topics are different (e.g. topic 2 includes introducing the concept, topic 5 reviewing and focusing the concept and topic 8 reviewing the concept). Table 1 presents an example (topic 7) of the analysis of forms of interaction and types of classroom discourse in episode 1. Topic 7 was chosen because it includes a typical example of student initiative (turn 24) and teacher feedback in a dialogic discussion (turns 25-27).

Table 1. Classroom discourse types in topic 7 of episode 1. The horizontal lines separate the interactions that were used in analysing the types of discourse at the micro-level. $(I=$ initiation by the teacher, $R=$ student's response, $E=$ evaluative feedback, $F=$ feedback that supplies elements for further extension, $S I=$ initiative by the student, $T=$ teacher; S1, S2, S3 and S4 = different students' statements)

\begin{tabular}{|c|c|c|c|c|}
\hline Turn & & & & $\begin{array}{c}\text { Discourse } \\
\text { type }\end{array}$ \\
\hline 1 & I & $\mathrm{T}:$ & $\begin{array}{l}\text { And then lever arms. Where are the lever arms? Can anybody else } \\
\text { explain but Mary? Okay, Mary can explain. }\end{array}$ & DD \\
\hline 2 & & S 1: & Well done, Mary. & \\
\hline 3 & $\mathrm{R}$ & S 2: & It is from that elbow to the hand... & \\
\hline 4 & $\mathrm{~F}$ & $\mathrm{~T}:$ & Can you explain it in a bit more detail? From the elbow... & \\
\hline 5 & $\mathrm{R}$ & S 2: & From the elbow. Then from there. & \\
\hline 6 & $\mathrm{~F}$ & $\mathrm{~T}:$ & Do you mean this fulcrum? & \\
\hline 7 & $\mathrm{R}$ & S 2: & From there. & \\
\hline 8 & $\mathrm{~F}$ & $\mathrm{~T}:$ & Yes. & \\
\hline 9 & $\mathrm{R}$ & S 2: & $\begin{array}{l}\text { From the fulcrum to there, what was that, regarding that force? Was } \\
\text { it the point of action of the force or middle point, or what was it? }\end{array}$ & \\
\hline 10 & $\mathrm{~F}$ & $\mathrm{~T}:$ & This point of action of the force, do you mean this? & \\
\hline 11 & $\mathrm{R}$ & S 2: & I don't know those terms. & \\
\hline 12 & $\mathrm{~F}$ & $\mathrm{~T}:$ & $\begin{array}{l}\text { Yes, yes. I'm just asking if you could tell us a little more precisely, } \\
\text { you know. }\end{array}$ & \\
\hline
\end{tabular}




\begin{tabular}{|c|c|c|c|c|}
\hline $\begin{array}{l}13 \\
14\end{array}$ & $\begin{array}{l}\mathrm{R} \\
\mathrm{E}\end{array}$ & $\begin{array}{l}\text { S 2: } \\
\text { T: }\end{array}$ & $\begin{array}{l}\text { Okay. } \\
\text { The perpendicular distance. This is the lever arm. The lever arm of } \\
\text { that palm and the weight. }\end{array}$ & \\
\hline 15 & I & $\mathrm{T}:$ & What else is there? Now we would still need another lever arm. & DD \\
\hline 16 & $\mathrm{R}$ & S 2: & Is it that upper arm then? & \\
\hline 17 & $\mathrm{~F}$ & $\mathrm{~T}:$ & The upper arm. What do you think? & \\
\hline 18 & $\mathrm{R}$ & S 2: & $\begin{array}{l}\text { Well, at least in that picture it is not possible, because it goes over } \\
\text { here like that. }\end{array}$ & \\
\hline 19 & $\mathrm{~F}$ & $\mathrm{~T}:$ & $\begin{array}{l}\text { In fact, there are still two lever arms. Now, here we have the point of } \\
\text { action of the force. When we have this kind of right angle here, it is } \\
\text { the perpendicular distance between the point of the action of the } \\
\text { force and the fulcrum. So, Mary, you can tell us. }\end{array}$ & \\
\hline 20 & $\mathrm{R}$ & S 2: & $\begin{array}{l}\text { Well, there is that other one from the forearm, from that arrow to that } \\
\text { fulcrum, and the other is that where that begins, that active muscle } \\
\text { force to the fulcrum. }\end{array}$ & \\
\hline 21 & $\mathrm{~F}$ & $\mathrm{~T}:$ & You mean here? & \\
\hline 22 & $\mathrm{R}$ & S 2: & Yes. & \\
\hline 23 & & T: & $\begin{array}{l}\text { So you have to have the lever arms of all the forces, all these } \\
\text { resistive forces and the active force. Here is one lever arm, here is } \\
\text { the other, and here is yet another. There are perpendicular distances } \\
\text { from all the points of action of the forces. Now we have three forces } \\
\text { here, so from all of them we have to draw the lever arm. }\end{array}$ & $\mathrm{TP}$ \\
\hline 24 & SI & S 3: & $\begin{array}{l}\text { If we didn't have this weight on that palm, would there be any lever } \\
\text { arm? }\end{array}$ & SI \\
\hline 25 & $\mathrm{~F}$ & $\mathrm{~T}:$ & $\begin{array}{l}\text { Well, possibly not. It depends. We could then also draw the lever } \\
\text { arm from the palm. We could consider the palm separately even if } \\
\text { there were not any weight. }\end{array}$ & DD \\
\hline 26 & $\mathrm{R}$ & S 3: & So, in principle, because of the weight, there is that lever arm? & \\
\hline 27 & $\mathrm{E}$ & $\mathrm{T}:$ & Not just because of that. & \\
\hline 28 & & $\mathrm{~T}:$ & $\begin{array}{l}\text { In a way, it would make it easier if we would calculate these. It } \\
\text { would make the calculations easier, if we had two lever arms here. } \\
\text { But even if there weren't any extra weight, we could draw a } \\
\text { downward arrow from every part of the body. From every centre of } \\
\text { gravity of every part of the body, we can draw an arrow downwards. } \\
\text { So, for every part of the body, we can define the centre of gravity. }\end{array}$ & $\mathrm{TP}$ \\
\hline
\end{tabular}

Comments at the micro-level: In turns 1-14 and 15-22, the teacher uses dialogic discussion to find out about students' conceptions of the topic to be learnt. Turns 23 and 28 are teacher presentations (TP) that are used to make a synoptic summary and to draw conclusions concerning the topics discussed. In other words, after opening up the space for exploring the students' views, the teacher begins to close down by taking more control over the discussions. Thus, this part conforms to the cumulative rhythm introduced in the theoretical framework. Cumulation is also present in terms of taking account of student views when moving to scientific closures, which is also realised by different types of discourse for these purposes.

Turn 24 is a student's initiative (SI), since the student raises a question to make the point discussed more precise. The teacher's answer (25) to the student's question is dialogic, since the teacher continues the discussion based upon the student's initiative. The student's initiative and following non-evaluative feedback could signal that the after dialogic discussions space is still open for student queries. On the other hand, the fact that the student wants a more precise elaboration of the scientific closure stresses the crucial role of making sufficient conclusions after dialogic discussions. 
To relate the variation of discourse types (rhythm) to the purpose of the whole, episode 1 is presented graphically in Figure 1. In order to render the temporality and shifts in classroom discourse types more visible, and to make the shifts along relatively short timescales easier to follow, the shifts between different types of talk are indicated by chaining arrows.

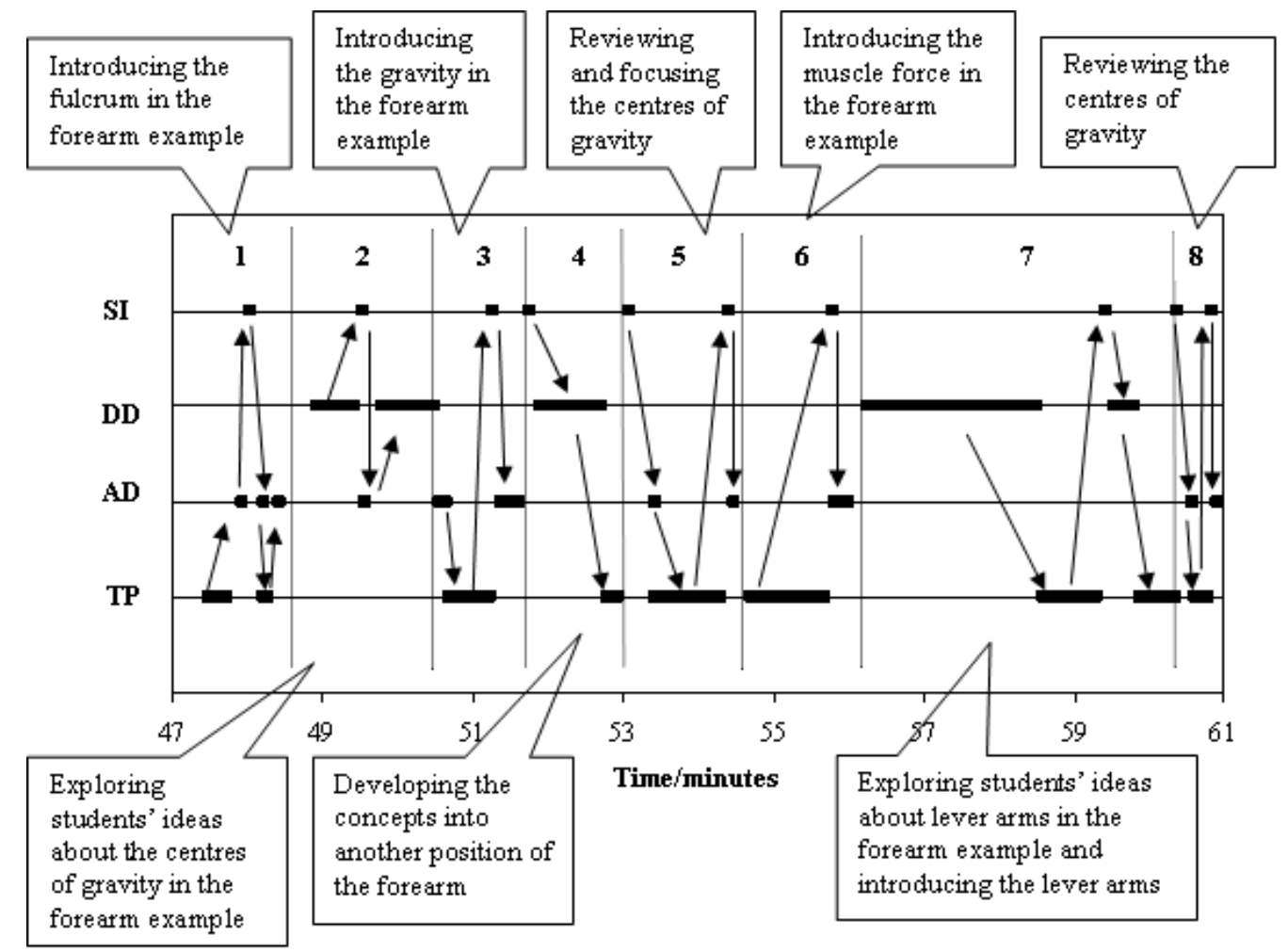

Figure 1. Types of classroom discourse, duration of discourse types and the sub-content and purpose of topics (1-8) in episode $1 . T P=$ teacher presentation, $A D=$ teacherguided authoritative discussion, $D D=$ teacher-guided dialogic discussion, $S I=$ student's initiative.

Comments at the meso-level: This level of analysis includes the identification of distinct rhythms of discourse. As the analysis of the interaction forms and related discourse types in the previous example reveals, the shifts in discourse types form the cumulative rhythm of teacher talk in topic 7 . In the cumulative rhythm, indicated by different discourse types, $\mathrm{DD}$ is followed by $\mathrm{TP}$ or $\mathrm{AD}$. If we are thinking about the overall rhythm in topic 7, it would assemble as DD-TP-SI-DD-TP. This rhythm includes the cumulative rhythm actually taking place before and after the student initiative. Scrutiny of the figure reveals similar properties in topic 4 , in which the student initiative (SI) is followed by dialogic discussions (DD) before finally closing the topic through teacher presentation (TP). 
Another distinct feature in episode 1 is that student initiative was often followed by $\mathrm{AD}$, which indicates firm control over the directions of the discussions, which does not foster the cumulative rhythm of talk types. Instead, the overall rhythm could be related to teacher-directed authoritative discussions. This feature is depicted in topics 1 , 3, 5, 6 and 8. Differing from the previous topics in which authoritative discourse types are prevailing, in topic 2, the overall discussions are considered as dialogic. The authoritative part within the dialogic discussions could resemble an "authoritative passage" guiding the talk "back on track". And, highlighting the dialogic aspect of discussions, the term guiding is preferred to directing.

When addressing the relationship between the purposes of the talk and discourse types, it can be interpreted that the purposes of introducing (topics 1, 3 and 6) and reviewing (topics 5 and 8 ) are closely related to authoritative discourse types (AD and TP) dominant within the topic. Instead, exploring (topics 2 and 7) seems to relate to prevailing dialogic discussions. Now, when thinking about the cumulativity between topics, for instance topic 2, where the ideas of centre of gravity are explored, the discussion is related to topic 5, where these concepts are reviewed with teacher presentation (TP). Thus, there is cumulation between topics 2 and 5, in terms of opening up and closing down discussions with different prevailing discourse types.

As scrutiny of the figure reveals distinct rhythms realised by shifts in talk types, at this level we are not, however, entitled to confirm whether there is cumulation within or between topics without the micro-level analysis of the contents. As the focus of the paper is on introducing the methodology, this issue is not addressed further in this paper.

\subsection{Episode 2}

In episode 2, the experimental group work that students undertook in episode 3 was summarised. A teacher-guided summary was made concerning the observations and concepts learned in the experimental work (e.g. line of action of force, lever arm, moment of force, and the moment rule). The aims of the episode were to ensure that students understood the concepts, to confirm the correctness of students' ideas and to correct the possible misconceptions students had constructed during the experimental work. The main reason for selecting this episode as an example was the rhythm of discourse, which is repeated several times. The duration of episode 2 was about seven minutes.

Episode 2 was divided into six topics (Figure 2). Table 2 presents topic 3 as an example of the discourse in episode 2, since the discourse types and the rhythm of discourse it includes also typify other topics within episode 2. 
Table 2. Classroom discourse types in topic 3 of episode 2. The horizontal lines separate the interactions that were used in analysing the types of discourse at the micro-level. $(I=$ initiation by the teacher, $R=$ students' response, $E=$ evaluative feedback, $F=$ feedback that supplies elements for further extension, $S I=$ initiative by the student, $T=$ teacher; S1, S2, S3, S4 and S5 = different students' statements)

\begin{tabular}{|c|c|c|c|c|}
\hline Turn & & & & $\begin{array}{l}\text { Discourse } \\
\text { type }\end{array}$ \\
\hline 1 & I & $\mathrm{T}:$ & $\begin{array}{l}\text { If we think now, what happens when we have weights with the same } \\
\text { mass here? What kind of observations did you make in that situation? } \\
\text { You can tell us, Rob. You know, you just told me that. }\end{array}$ & $\mathrm{AD}$ \\
\hline 2 & $\mathrm{R}$ & S1: & $\begin{array}{l}\text { Then, the lengths of the lever arms must also be equal, if the weights } \\
\text { have the same mass. }\end{array}$ & \\
\hline 3 & $\mathrm{E}$ & $\mathrm{T}:$ & $\begin{array}{l}\text { Yes. Both of the weights are fifty grams, and so the lengths of the } \\
\text { lever arms are also equal. }\end{array}$ & \\
\hline 4 & I & $\mathrm{T}:$ & How did you measure the lever arm? & $\mathrm{DD}$ \\
\hline 5 & $\mathrm{R}$ & S2: & Using the perpendicular distance of the line of action... & \\
\hline 6 & $\mathrm{R}$ & S3: & The perpendicular distance from it. & \\
\hline 7 & $\mathrm{~F}$ & $\mathrm{~T}:$ & The perpendicular distance from where? & \\
\hline 8 & $\mathrm{R}$ & S4: & From that line, what was it... & \\
\hline 9 & $\mathrm{R}$ & S5: & The line of action. & \\
\hline 10 & $\mathrm{R}$ & S4: & The perpendicular distance between the line of action and... & \\
\hline 11 & $\mathrm{~F}$ & $\mathrm{~T}:$ & Yes. & \\
\hline 12 & $\mathrm{R}$ & S4: & ...the centre of gravity...or that point, the fulcrum. & \\
\hline 13 & & $\mathrm{~T}:$ & $\begin{array}{l}\text { So, here we have the line of action of the force. This weight acts } \\
\text { here, and here is the point of action where this weight acts; and from } \\
\text { there, the line of action goes straight to here. And the perpendicular } \\
\text { distance that you measured from here is this distance from the } \\
\text { fulcrum; and the fulcrum is here where the rotation takes place. }\end{array}$ & TP \\
\hline
\end{tabular}

Comments at the micro-level: The rhythm of discourse in topic 3 follows the pattern AD-DD-TP (Table 2, Fig. 2). By using teacher-guided authoritative discussion (AD), the teacher begins the review of the lever arms. This could be considered as a prephase for dialogic discussions since the teacher is setting the norms and boundaries for the following discussions (Tiberghien \& Malkoun, 2009). With dialogic discussion (DD), the teacher tries to find out the students' conceptions and observations regarding the lever arm. If we study only the transcribed data, the discussion type could be interpreted as an authoritative discussion (AD), since the teacher's feedback (turn 11) seems to be evaluative. Video-recorded data, however, makes it explicit that the feedback is not evaluative, as the teacher signals approval to encourage the student to continue his answer. Briefly, in this manner, the teacher validates the student's response by recognition rather than evaluative feedback (Cf. Berland \& Hammer, 2012). At the end of the topic, the teacher reviews the lever arms with TP.

Overall, the rhythm of the example topic resonates with the cumulative one, with one pre-mentioned exception compared to the first example: the opening-up phase includes the teacher foregrounding the dialogic discussions via more authoritative discussions. 


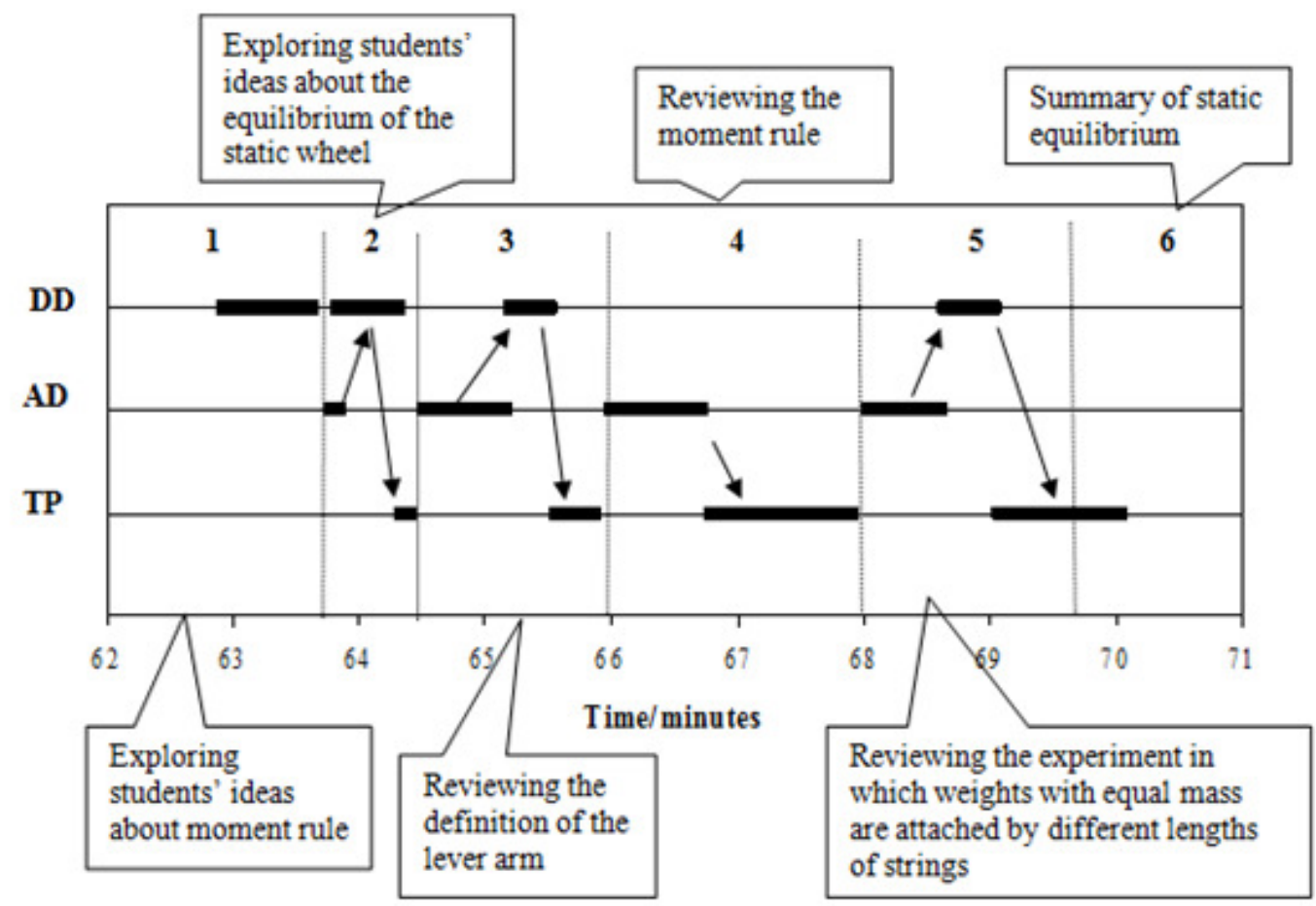

Figure 2. Types of classroom discourse, duration of discourse types, and the sub-content and purpose of topics (1-6) in episode 2. TP = teacher presentation, $A D=$ teacherguided authoritative discussion, $D D=$ teacher-guided dialogic discussion.

Comments at the meso-level: In addition to the confirmed cumulative structure illustrated in Table 2, the lesson Figure 2 depicts also topics 2 and 5, which resemble the following cumulative rhythm in discourse types:

- TP/AD (for setting boundaries for discussion)

- DD (for opening up discussions)

- TP/AD (for closing down discussions)

Differing from the cumulative rhythm illustrated within episode 1, in episode 2 the rhythms indicating cumulation consist of the teacher setting norms for the discussions. Or, as Tiberghien and Malkoun (2009) phrase it, the teacher could be introducing the 'didactic contract' and in this way is expecting students to stay on certain topic areas in discussions. When taking a look at the purposes of the talk, it can be seen that whereas in episode 1, dialogic discussions were related to the exploration of students' views, in this episode it is taking place when reviewing (topics 3 and 5). This could explain the prevailing authoritativeness in these two topics when related to the ones in episode 1 and to topic 2 in episode 2 . In other words, despite the cumulative rhythm in topics 3 and 5 , students' views have already been explored or the content has been otherwise introduced, thus targeting the focus more on the scientific view and conclusions through more authoritative discussions. 
Having said this, when thinking about cumulation between topics, by examining more closely the purposes it seems that topic 1 closed down in topic 4 . Thus, in a wider temporal scale, the authoritativeness in topic 4 is standing for closing down the previous discussions in which dialogic discussions are prevailing. Thus, the cumulative rhythm is interpreted also in a broader temporal scale between topics 1 to 4 , which is realised with different purposes of the talk linked to different prevailing discourse types in topics.

When commenting briefly at the macro-level, both of the example episodes resemble varying communication styles constituting different types of talk. Thus, besides detecting several instances of shifts in talk type constituting the cumulative rhythm of teacher talk, the talk varies between authoritative (includes teacher presentation) and dialogic in other ways also. One overall difference between the two episodes is the student initiatives are missing from episode 2, whereas they emerged frequently during episode 1.

\section{Discussion}

The multi-level analysis of classroom communication applied in this study offers a means to support and illustrate a detailed exploration of classroom communication by drawing on the cumulative descriptions of teacher talk. The examples of the transcriptions provided information on how the teacher establishes the cumulative rhythm of talk, which addressed the micro-level of analysis. Continuing with the scrutiny of the figures of the example episodes, similar rhythms were pointed out at the meso-level (the cyclic rhythm AD-DD-TP found especially in episode 2). The overall (macro-level) exploration of the episodes reveals the teacher applying varying forms of talk, which has been related to teaching that is beneficial for student learning outcomes (Furtak \& Shavelson, 2009). In particular, the cumulative rhythm of teacher talk resonates with the idea of the meaningful learning of science, in which student contributions are considered as a part of the meaning-making processes (Scott \& Ametller, 2007).

In addition to the distinct cumulative rhythm found in the lesson figures, other distinct features revealed at the meso-level consisted of the teacher responding to student initiatives with different types of talk. Whenever student initiative was followed by an authoritative type of talk or teacher presentation, it could be assumed that the temporal surrounding of the emerging initiative was also authoritative. In other words, the teacher maintained control over the discussions rather than seeing this as an opportunity to explore students' ideas further.

As an interesting example, one student initiative in the middle of an extended dialogic discussion (episode 1, topic 2) was followed by an authoritative turn. When thinking about the temporal surrounding of this exact initiative, the initiative and teacher feedback could signal the student being unsure of the aims of the dialogic discussions. In relation to this notion, if the teacher does not state the subject to have been learned clearly (by using teacher-guided authoritative discussion or teacher presentation), the students may remain in a confused state regarding the subject matter. Students want to be sure about what is correct, and if the subjects being taught are discussed only by using teacher-guided dialogic discussion, and then some important points may remain unclear to students (Ryder et al., 2003). This is also an essential notion within the cumulative 
framework: If topics are opened up for dialogic discussion, they should also be closed down with enough elaboration on the scientific accuracy.

Without discussing further the specifics of the student initiatives detected in this study, we focus more on the general implications of the methodology. The approach illustrated in this study could reveal the critical moments (Cf. Myhill, 2006), such as students' initiatives, in which the teacher fails to follow up any opportunities to explore the students' thinking, in this way thereby further opening up dialogic discussions. Or, instead, the teacher could confirm the students' questions with more authoritative types of talk. The scrutiny of the temporal context of the critical moments could unveil more of the relationship between specific purposes and the nature of the discourse.

More generally, targeting the explorations from a meso- to a more micro-level (or vice versa, expanding from micro- to meso-level) analysis of the interactions could provide insights into the need for the use of different types of classroom discourse for different purposes at a more macro-level. Meaning, scrutiny of the interactions could expand from turns, topics and episodes even towards examining the entities of teaching sequences, courses and so on. Having said this, whereas the meso-level for instance could be optional for detecting certain distinct features and rhythms of teacher talk such as are introduced in this study, the intentness and purposefulness may only be approached through an elaboration of different levels of analysis (Klette, 2009). Moreover, as Scott and colleagues (2006) say in more general terms, "to understand the purpose of a specific teaching activity in a sequence of lessons it is necessary to determine how this particular activity fits with the whole sequence" (p. 626). We consider that not only looking back and forth, but also expanding and narrowing the temporal scale of analytical units would be as important when studying the specific properties of classroom interactions.

As the multiple time-scales in this study are covering teaching from turns and sentences to the episode level, it should be noted that the definitions and the temporal range of the different analytical levels depend on the research aims. For instance, if teaching would be evaluated more at the level of overall teaching sequences and courses (Cf. Scott, Mortimer, \& Ametller, 2011), then analytical levels should be defined based upon these aims.

\section{Conclusions}

Our present study provides useful examples of practices that could be used to stimulate discussion and reflection within teacher education, and/or it could be used by qualified teachers who wish to reflect on their existing teaching practices and how they might pursue cumulative and meaningful teaching. The information and the examples of practices, which demonstrate the connection between cumulation and classroom discourse types may offer teachers and teacher educators new practical insights into the processes of cumulation and classroom discourse. The knowledge of different purposes and types of classroom discourse and cumulation may help the teacher to design lesson contents and teaching methods, and to steer the classroom discourse in a purposeful manner, taking the pedagogical aim of the teaching into account.

Indeed, particularly in the light of teacher education, the presentation of information in lists and tables does not illustrate the dynamic aspect of classroom interaction; that is, how talk develops and how talk can be viewed alongside pedagogic 
intent. A visual presentation of this information conforms to a broader notion of classroom communication as non-monotonic and how instructional communication should vary between different types of talk. Furthermore, the visualization of teacher talk supports the understanding of classroom interactions as more dynamic and manageable rather than unfolding only on a moment-by-moment basis.

The analysis method used in this study provides teachers with tools to examine and possibly modify their classroom practices, which, according to Scott et al. (2006), is important if teachers and students are to be supported to engage in meaningful social interactions in the classroom context. Our multiple timescale analysis of classroom discourse may also assist teachers to attend to aspects of cumulative teaching.

\section{References}

Aguiar, O. G., Mortimer, E. F., \& Scott, P. (2010). Learning from and Responding to Students' Questions: The Authoritative and Dialogic Tension. Journal of Research in Science Teaching, 47(2), 174-193.

Alexander, R. (2004). Towards Dialogic Teaching: Rethinking Classroom Talk. Cambridge: Dialogos.

Andersen, H. M., \& Nielsen, B. L. (2011). Video-Based Analyses of Motivation and Interaction in Science Classrooms. International Journal of Science Education, 123.

Berland, K. B., \& Hammer, D. (2012). Framing for Scientific Argumentation. Journal of Research in Science Teaching, 49(1), 68-94.

Cazden, C. B. (1986). Classroom discourse. In M. C. Wittrock (Ed.), Handbook of Research on Teaching, 3rd edition, 432-463. New York: Macmillan.

Cullen, R. (2002). Supportive teacher talk: the importance of the follow-up. ELT Journal, $56(2), 117-127$.

Furtak, E. M., \& Shavelson, R. J. (2009). Guidance, Conceptual Understanding, and Student Learning: An Investigation of Inquiry-Based Teaching in the US. In T. Janik, \& T. Seidel (Eds.), The Power of Video Studies in Investigating Teaching and Learning in the Classroom, 181-203. Münster: Waxmann Publishing Co.

Klette, K. (2009). Challenges in Strategies for Complexity Reduction in Video Studies. Experiences from the PISA+ Study: A Video Study of Teaching and Learning in Norway. In T. Janik, \& T. Seidel (Eds.), The Power of Video Studies in Investigating Teaching and Learning in the Classroom, 61-82. Münster: Waxmann Publishing Co.

Leach, J., \& Scott, P. (2003). Individual and sociocultural views of learning in science education. Science \& Education, 12, 91-113.

Mercer, N. (2004). Sociocultural discourse analysis: analysing classroom talk as a social mode of thinking. Journal of Applied Linguistics 1(2), 137-168.

Mercer, N., Daves, R., Wegerif, R., \& Sams, C. (2004). Reasoning as a scientist: ways of helping children to use language to learn science. British Educational Research Journal, 30(3), 367-385.

Mercer, N., \& Littleton, K. (2007). Dialogue and the Development of Children's Thinking: A Sociocultural Approach. London: Routledge. 
Mercer, N., Littleton, K., \& Wegerif, R. (2004). Methods for studying the processes of interaction and collaborative activity in computer-based educational activities. Technology, Pedagogy and Education, 13(2), 193-209.

Mortimer, E. F., \& Machado, A. H. (2000). Anomalies and conflicts in classroom discourse. Science Education, 84, 429-444.

Mortimer, E. F., \& Scott, P. (2003). Meaning Making in Secondary Science Classrooms. Maidenhead: Open University Press.

Myhill, D. (2006). Talk, talk, talk: Teaching and learning in whole class discourse. Research Papers in Education, 21(1), 19-41.

Nassaji, N. \& Wells, G. (2000). What's the use of 'triadic dialogue'? An investigation of teacher-student interaction. Applied Linguistics, 21(3), 376-406.

Nurkka (2006). Developing and evaluating a research-based teaching-learning sequence on the moment of force. Doctoral thesis (in Finnish). University of Jyväskylä. Department of Physics. Research report no.10/2006. Jyväskylä.

Polman, J. L. (2004). Dialogic activity structures for project-based learning environments. Cognition and Instruction, 22(4), 431-466.

Ryder, J., Hind, A., \& Leach, J. (2003). Enacting lesson resources for teaching about the nature of theoretical models in high school science classrooms. Paper presented in the symposium, 'Teaching about science: Lessons from classroom research' at the annual meeting of the National Association for Research in Science Teaching, Philadelphia, March 2003.

Scott, P. (2008). Talking a way to understanding in science classrooms. In N. Mercer, \& S. Hodgkinson, (Eds.), Exploring talk in school, 17-36. London: SAGE.

Scott, P., \& Ametller, J. (2007). 'Teaching science in a meaningful way: striking a balance between "opening up" and "closing down" classroom talk'. School Science Review, 88(324), 77-83.

Scott, P., Mortimer, E. F., \& Aguiar, O. G. (2006). The tension between authoritative and dialogic discourse: A fundamental characteristic of meaning making interactions in high school science lessons. Science Education, 90, 605-631.

Scott, P., Mortimer, E. F, \& Ametller, J. (2011). Pedagogical Link-Making: A Fundamental Aspect of Teaching and Learning Scientific Conceptual Knowledge. Studies in Science Education, 47(1), 3-36.

Sinclair, J.M., \& Coulthard, R.M. (1975). Towards an Analysis of Discourse: The English Used by Teachers and Pupils. London: Oxford University Press.

Tiberghien, A., Buty, C., \& Le Maréchal, J.-F. (2004). Physics teaching sequences and students' learning. Manuscript for the proceedings of the 2nd Conference of EDIFE and the 2nd IOSTE Symposium in Southern Europe, Kalamata, Greece, March 18-20, 2004.

Tiberghien, A., \& Malkoun, L. (2009). The construction of physics knowledge in a classroom community from different perspectives. In B. Schwarz, T. Dreyfus \& R. Hershkovitz (Eds.), Transformation of Knowledge through Classroom Interaction (pp. 42-55). New York: Routledge.

Viiri, J., \& Saari, H. (2006). Teacher talk patterns in science lessons. Use in teacher education. Journal of Science Teacher Education, 17, 347-365.

Vygotsky, L.S. (1978). Mind in Society. Cambridge, MA: Harvard University Press. 
Wells, G. (1999). Dialogic Inquiry: Towards a Sociocultural Practice and Theory of Education. Cambridge: Cambridge University Press. 